\title{
Генерация и детектирование терагерцевого излучения в низкотемпературных эпитаксиальных пленках GaAs на подложках GaAs с ориентациями (100) и (111)A
}

\author{
(C) Г.Б. Галиев ${ }^{1}$, С.С. Пушкарёв ${ }^{1, \uparrow, ~ А . М . ~ Б у р я к о в ~}{ }^{2}$, В.Р. Билык ${ }^{2}$, Е.Д. Мишина ${ }^{2}$, \\ Е.А. Климов ${ }^{1}$, И.С. Васильевский ${ }^{3}$, П.П. Мальцев ${ }^{1}$ \\ ${ }^{1}$ Институт сверхвысокочастотной полупроводниковой электроники Российской академии наук, \\ 117105 Москва, Россия \\ ${ }^{2}$ Московский технологический университет „МИРЭА“, \\ 119454 Москва, Россия \\ ${ }^{3}$ Национальный исследовательский ядерный университет „МИФИ“, \\ 115409 Москва, Россия \\ ๑ E-mail: s_s_e_r_p@mail.ru
}

(Получена 20 сентября 2016 г. Принята к печати 26 сентября 2016 г.)

\begin{abstract}
Методом терагерцевой спектроскопии исследована эффективность генерации и детектирования ТГцизлучения в диапазоне до 3 ТГц пленками LT-GaAs, содержащими легирующие эквидистантные $\delta$-слои $\mathrm{Si}$ и выращенными методом молекулярно-лучевой эпитаксии на подложках GaAs с ориентациями (100) и (111)А. На поверхности пленок были изготовлены микрополосковые фотопроводящие антенны. Генерация ТГц-излучения происходила при облучении зазора антенны фемтосекундными оптическими лазерными импульсами. Показано, что интенсивность ТГц-излучения от фотопроводящей антенны на LT-GaAs/GaAs (111)A в 2 раза больше, чем от такой же антенны на LT-GaAs/GaAs $(100)$, а чувствительность антенны на LT-GaAs/GaAs(111)A как детектора ТГц-излучения в 1.4 раза превосходит чувствительность антенны на LT-GaAs/GaAs (100).
\end{abstract}

DOI: $10.21883 /$ FTP.2017.04.44347.8408

\section{1. Введение}

Терагерцевая спектроскопия с временны́м разрешением - актуальный и активно развивающийся в настоящее время метод диагностики различных материалов и биологических объектов с помощью малоинтенсивного электромагнитного излучения терагерцевого диапазона частот (100 ГГц-3 ТГц). Для генерации и детектирования терагерцевого излучения в этом методе используются фотопроводящие антенны (ФП антенны) на основе специфических полупроводниковых материалов. Такие материалы должны обладать либо малым временем релаксации импульса фотовозбужденных носителей заряда, либо их малым временем жизни. К первому типу материалов относятся бездефектные монокристаллические пленки GaAs [1], а ко второму - пленки $\mathrm{GaAs}$, выращенные методом молекулярно-лучевой эпитаксии при пониженной температуре подложки (lowtemperature GaAs, LT-GaAs) [2].

Пониженная температура роста приводит к тому, что реиспарение мышьяка с поверхности растущей пленки подавлено, и она захватывает до $1.5 \%$ избыточных атомов мышьяка (в то время как в стехиометрическом соединении GaAs атомов $\mathrm{Ga}$ и As ровно по 50\%) [3-5]. Вследствие этого пленка LT-GaAs обладает высокой концентрацией антиструктурных дефектов $\mathrm{As}_{\mathrm{Ga}}$ (атом As в узле атома $\mathrm{Ga}$ ) порядка $10^{20} \mathrm{~cm}^{-3}$ [6]. В заряженном состоянии $\mathrm{As}_{\mathrm{Ga}}^{+}$эти дефекты действуют как ловушки для электронов и тем самым обеспечивают крайне малое время жизни фотовозбужденных электронов (менее пикосекунды) [7].
Для увеличения концентрации заряженных дефектов $\mathrm{As}_{\mathrm{Ga}}^{+}$материал LT-GaAs легируют акцепторной примесью (как правило, бериллием) [7]. В работах $[8,9]$ показано, что структуры LT-GaAs:Be могут быть использованы в оптоэлектронных устройствах терагерцевого диапазона частот, причем такие устройства имеют лучшие параметры по сравнению с устройствами на базе нелегированного LT-GaAs. Однако из-за высокой токсичности Ве его использование при молекулярнолучевой эпитаксии (МЛЭ) в последнее время снижается и мало распространено в промышленном производстве, поскольку требует дополнительных мер безопасности. Кроме того, наличие в установке МЛЭ источника Ве приводит к повышению фоновой примеси $p$-типа, что отрицательно сказывается на качестве в последующем выращиваемых в ней гетероструктур n-типа (например, НЕМТ-гетероструктур с высокой подвижностью электронов).

Хорошо известно, что кремний проявляет ярко выраженные амфотерные свойства как легирующая примесь в эпитаксиальных пленках GaAs, выращенных на подложкаx GaAs с кристаллографической ориентацией (111)A при стандартных температурах роста $\left(500-600^{\circ} \mathrm{C}\right)$. В этом случае, меняя соотношение потоков мышьяка и галлия $\gamma$, на подложке GaAs (111)A можно вырастить легированные кремнием слои $\mathrm{GaAs}$ как с $n$-, так и с $p$-типом проводимости $[10,11]$. Однако легирующие свойства Si в пленках LT-GaAs, выращенных на подложке GaAs (111)A, ранее не исследовались.

В данной работе исследуются генерация и детектирование терагерцевого излучения фотопроводящими 
антеннами на пленках LT-GaAs, эпитаксиально выращенных на подложках GaAs как со стандартной кристаллографической ориентацией (100), так и с ориентацией (111)A и легированных атомами Si. Цель работы установить, на какой подложке эпитаксиальная пленка LT-GaAs обладает лучшими свойствами как материал для фотопроводящей терагерцевой антенны. При этом имеется в виду, что на свойства пленки LT-GaAs влияет не только возможное проявление амфотерности атомов $\mathrm{Si}$, но и особенности кристаллической структуры, приобретаемые пленкой LT-GaAs при росте на разных подложках. Кроме того, свойства исследуемых ФП антенн сравниваются со свойствами традиционно применяемого для тех же целей нелинейного кристалла ZnTe.

\section{2. Образцы и методика эксперимента}

Исследуемые в данной работе образцы одинакового дизайна были выращены на полуизолирующих подложках $\mathrm{GaAs}(100)$ и (111)A методом молекулярнолучевой эпитаксии. Образец на подложке GaAs (100) обозначается в дальнейшем LT-GaAs/GaAs (100) (номер ростового процесса 975-3.3), а образец на подложке GaAs (111)A - LT-GaAs/GaAs (111)A (номер ростового процесса 978-6.3). Дизайн образцов представлен на рис. 1. Образцы состоят из двух слоев: слоя $i$-GaAs толщиной 0.2 мкм, выращенного при температуре $560^{\circ} \mathrm{C}$, и слоя LT-GaAs толщиной 1 мкм, выращенного при температуре $230^{\circ} \mathrm{C}$. Слой LT-GaAs содержит три $\delta$-слоя кремния, расположенных на расстоянии 0.255 мкм друг от друга. Концентрация атомов $\mathrm{Si}$ в каждом из $\delta$-слоев указана на рис. 1. Отношение потоков $\mathrm{As}_{4}$ и $\mathrm{Ga}$ во время роста составляло $\sim 20$. После роста образцы были подвергнуты отжигу в камере роста установки молекулярно-лучевой эпитаксии в потоке $\mathrm{As}_{4}$ при температуре $590^{\circ} \mathrm{C}$ в течение 1 ч. Морфология поверхности, кривые дифракционного отражения и спектры фотолюминесценции этих образцов обсуждаются в работе [12].

На поверхности выращенных образцов методом фотолитографии были изготовлены микрополосковые фотопроводящие антенны. Они представляли собой омические контакты Ti/Au (50/800 нм) в виде двух параллельных полосок шириной 100 мкм и с расстоянием между ними 200 мкм (рис. 2, $a$ ).

Экспериментальная установка для исследования генерации и детектирования ТГц-излучения показана на рис. 2, $b$. В качестве источника оптической накачки ФП антенн использовался твердотельный лазер на кристалле сапфира, легированного ионами титана, с длиной волны 800 нм (энергия фотона 1.55 эВ), длительностью импульса 100 фс и частотой следования импульсов 80 МГц. Плотность средней мощности накачки составляла $3.71 \cdot 10^{3} \mathrm{~B} / \mathrm{cm}^{2}$, зондирования $0.88 \cdot 10^{3} \mathrm{BT} / \mathrm{cm}^{2}$. Оптическое излучение накачки фокусировалось в пятно диаметром $\sim 12$ мкм между электродами ФП антенны. Для достижения оптимальных условий генерации ТГц-излучения пятно луча накачки было

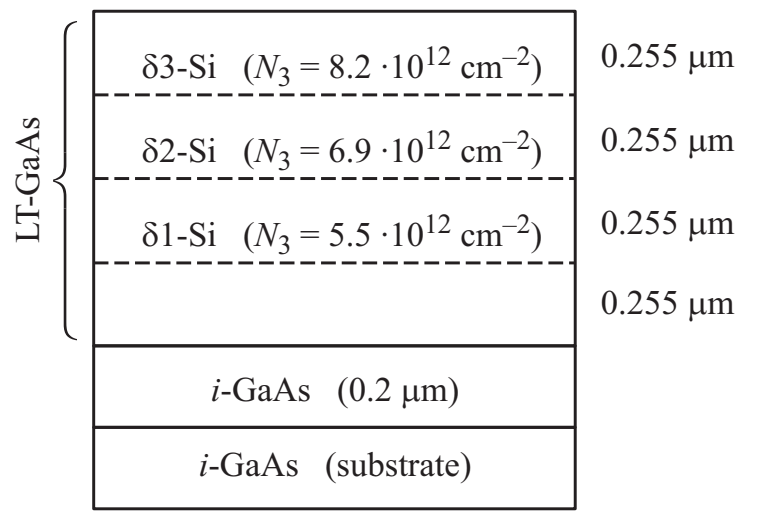

Рис. 1. Дизайн исследуемых образцов.

сдвинуто к анодному электроду ФП антенны, поскольку электрическое поле между двумя далеко отстоящими металлическими линейными электродами сильно неоднородно и концентрируется возле анода $[13,14]$.

Одни и те же изготовленные образцы ФП антенн на пленках LT-GaAs (100) и LT-GaAs (111)A тестировались как в режиме генерации, так и в режиме детектирования ТГц-излучения. В качестве эталонного генератора и детектора использовался нелинейный кристалл ZnTe. При генерации ТГц-излучения ФП антеннами к их контактам прикладывалось напряжение смещения, тем самым создавалось внешнее электрическое поле в зазоре между контактами, которое ускоряло фотовозбужденные носители заряда. Напряжение смещения варьировалось в диапазоне 0-60 В. При детектировании ТГц-излучения ФП антеннами напряжение смещения не прикладывалось, а фототок в антенне появлялся из-за действия на фотовозбужденные носители заряда электрического поля терагерцевого излучения. Этот фототок являлся электрическим сигналом терагерцевой частоты, полностью соответствующим детектируемому ТГц-импульсу. Для его измерения использовался синхронный усилитель SR 830, который позволяет извлечь сигнал с заданной длиной волны в зашумленной среде (даже тогда, когда шум и сигнал неразличимы во временно́й области, но сигнал имеет определенную полосу частот и нет больших пиков шума в пределах этого диапазона, то шум и сигнал могут быть отделены друг от друга).

В схеме с нелинейно-оптическим кристаллом ZnTe принцип детектирования ТГц-излучения основан на методе электрооптического стробирования широкого терагерцевого импульса короткими фемтосекундными импульсами $[15,16]$. Принцип работы основан на взаимодействии терагерцевого и оптического излучений в нелинейной среде за счет модуляции фазы оптического излучения терагерцевой волной. Сканирование фазы терагерцевой волны осуществляется с помощью временно́й линии задержки. В качестве детекторов и генераторов используют нелинейные кристаллы с высокой нелинейной восприимчивостью второго порядка $\mathrm{LiTaO}_{3}$, $\mathrm{LiNbO}_{3}, \mathrm{ZnTe}[14]$. 
$a$

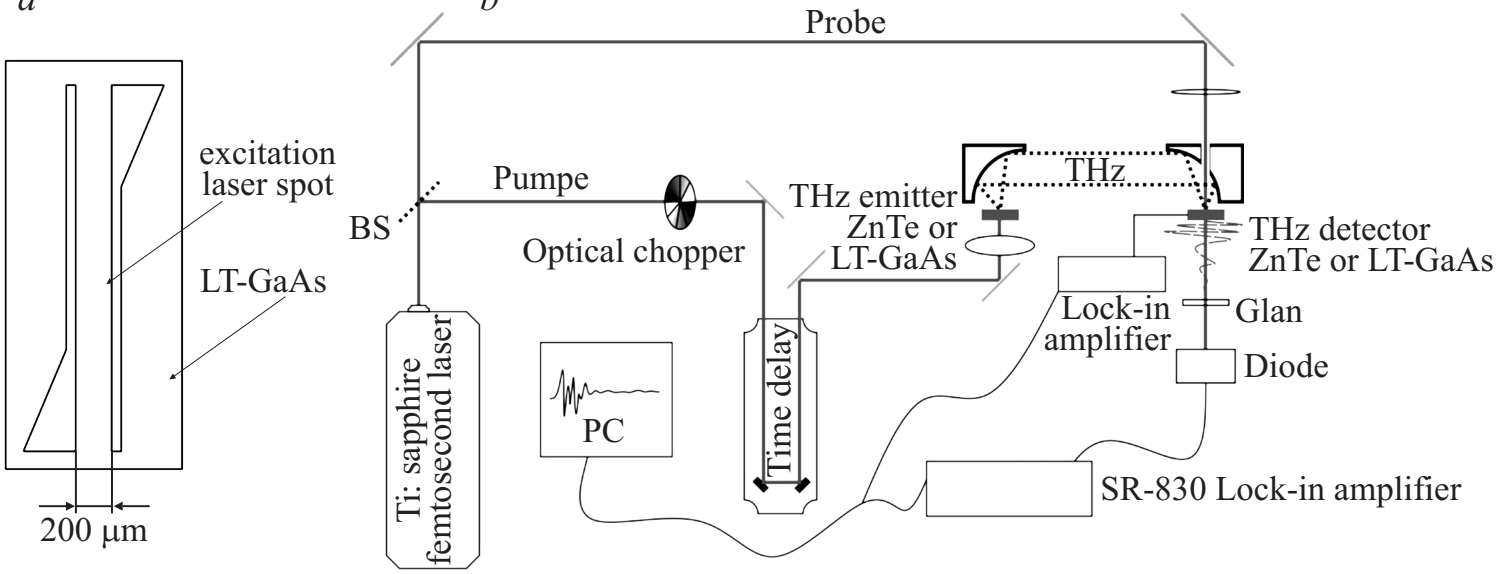

Рис. 2. Схема ФП антенн на LT-GaAs $(a)$ и экспериментальной установки для генерации и детектирования ТГц-излучения от нелинейного кристалла $\mathrm{ZnTe}(b)$.
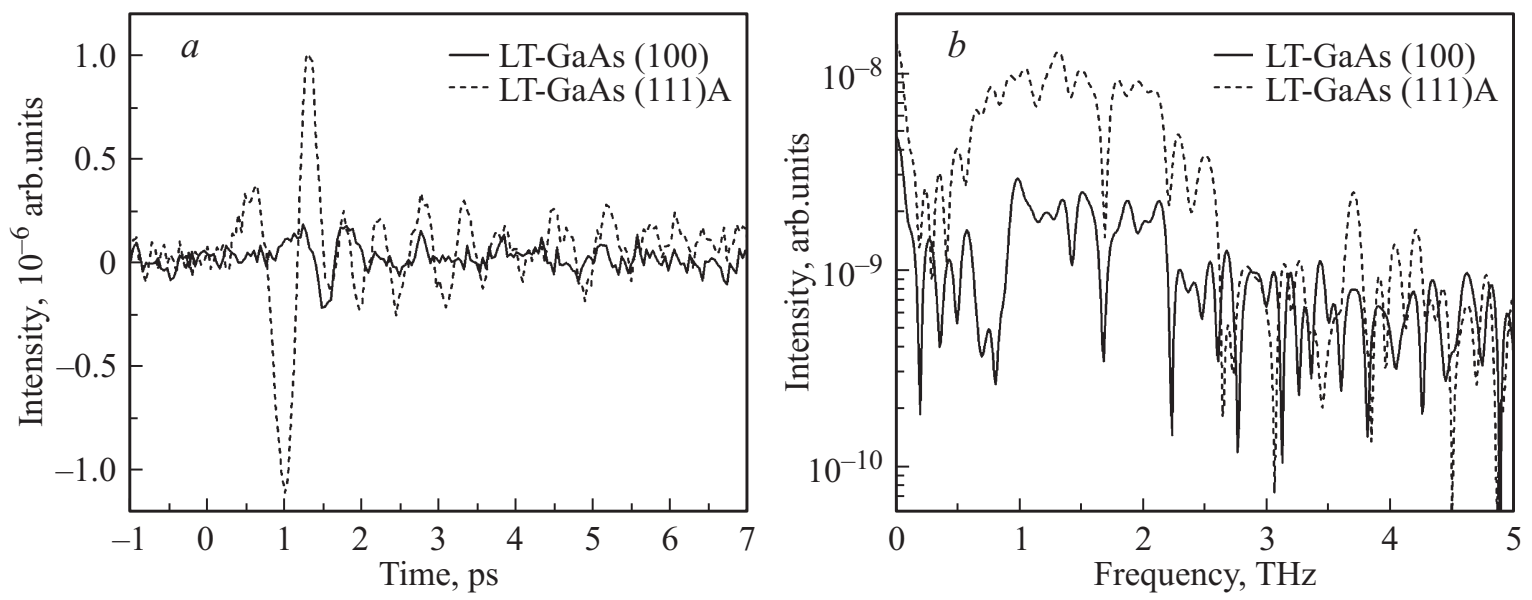

Рис. 3. Генерация ТГц-излучения пленками LT-GaAs без приложения внешнего электрического поля (детектор - кристалл ZnTe): $a$ - временна́я зависимость ТГц-излучения пленками LT-GaAs $(100)$ и (111)A; $b$ - частотный спектр ТГц-излучения.
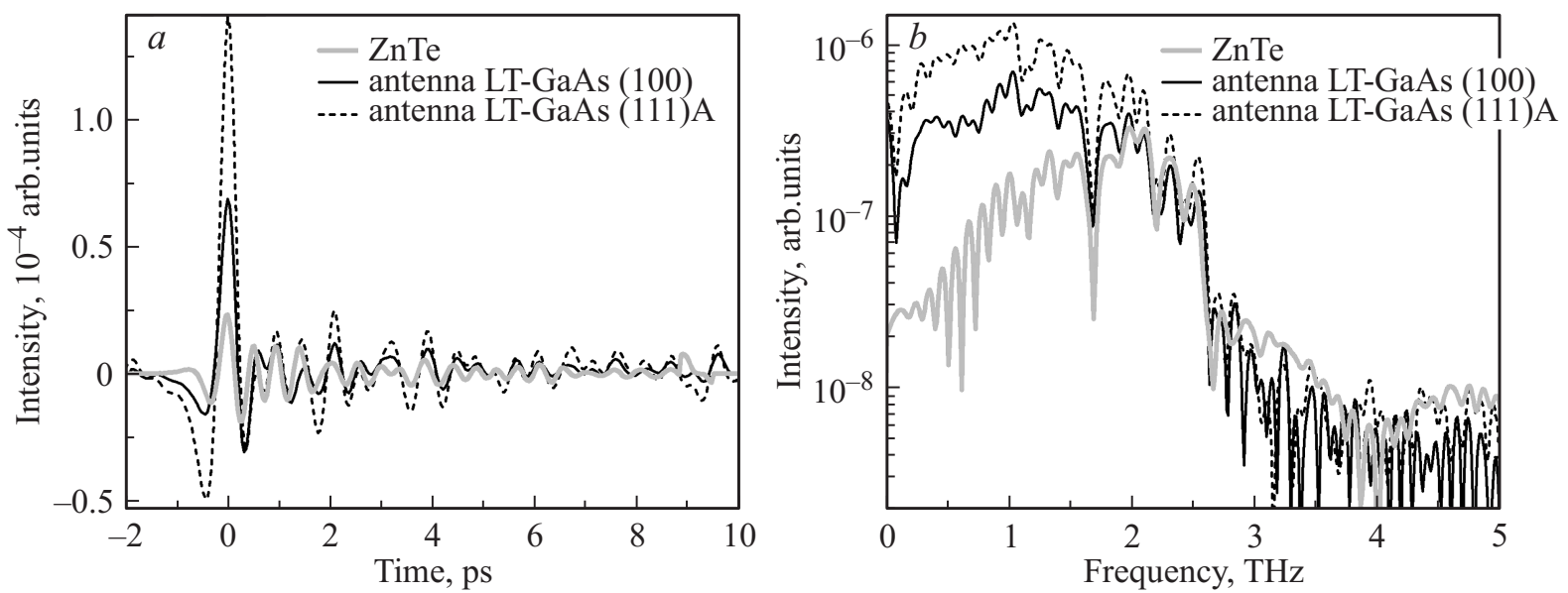

Рис. 4. Сравнение терагерцевых генераторов (детектор - кристалл ZnTe): $a$ - временна́я форма ТГц-импульса при приложении напряжения смещения $60 \mathrm{~B} ; b-$ спектр ТГц-излучения. 
Характеристики нелинейного кристалла ZnTe, пленок и ФП антенн, к которым приложено напряжение 60 B, в диапазоне частот $0-5$ ТГц

\begin{tabular}{|c|c|c|c|c|c|}
\hline & \multirow{2}{*}{ ZnTe } & \multicolumn{2}{|c|}{ Пленка LT-GaAs } & \multicolumn{2}{|c|}{ ФП антенна на LT-GaAs } \\
\hline & & $\begin{array}{l}\text { Подложка } \\
\text { GaAs (100) }\end{array}$ & $\begin{array}{c}\text { Подложка } \\
\mathrm{GaAs}(111) \mathrm{A}\end{array}$ & $\begin{array}{l}\text { Подложка } \\
\text { GaAs (100) }\end{array}$ & $\begin{array}{c}\text { Подложка } \\
\text { GaAs (111)A }\end{array}$ \\
\hline \multicolumn{6}{|c|}{ Генерация } \\
\hline $\begin{array}{l}\left(f_{1 / 2}\right)_{\min }, \text { ТГц* } \\
\left(f_{1 / 2}\right)_{\max }, \text { ТГц* } \\
\text { Ширина полосы излучения, ТГц } \\
\text { Нормированная интегральная } \\
\text { интенсивность ТГц-излучения }\end{array}$ & $\begin{array}{l}1.00 \\
2.37 \\
1.37 \\
1\end{array}$ & $\begin{array}{l}\sim 0.5^{* *} \\
\sim 3.5^{* *} \\
\sim 3.0^{* *} \\
\sim 0.014^{* *}\end{array}$ & $\begin{array}{l}0.60 \\
2.17 \\
1.57 \\
0.050\end{array}$ & $\begin{array}{l}0.42 \\
1.97 \\
1.55 \\
2.30\end{array}$ & $\begin{array}{l}0.28 \\
1.58 \\
1.30 \\
4.52\end{array}$ \\
\hline \multicolumn{6}{|c|}{ Детектирование } \\
\hline $\begin{array}{l}\left(f_{1 / 2}\right)_{\min }, \text { ТГц } \\
\left(f_{1 / 2}\right)_{\max }, \text { ТГц } \\
\text { Ширина полосы чувствительности, ТГц } \\
\text { Нормированная интегральная } \\
\text { чувствительность к ТГц-излучению }\end{array}$ & $\begin{array}{l}1.03 \\
2.32 \\
1.29 \\
1\end{array}$ & $\begin{array}{l}- \\
- \\
- \\
-\end{array}$ & $\begin{array}{l}- \\
- \\
- \\
-\end{array}$ & $\begin{array}{l}0.83 \\
2.13 \\
1.30 \\
1.28\end{array}$ & $\begin{array}{l}0.81 \\
2.13 \\
1.32 \\
1.80\end{array}$ \\
\hline
\end{tabular}

Примечание.* Погрешность определения частоты составляет \pm 0.04 ТГц. ** Величины указаны оценочно, так как малая интенсивность сигнала затрудняла анализ его спектра.

\section{3. Результаты и обсуждение}

На рис. 3 показаны временны́е формы и частотные спектры ТГц-излучения от ФП антенн без приложения напряжения к их контактам. В качестве детектора использовался кристалл ZnTe. В данном случае происходила генерация ТГц-излучения фотовозбужденными носителями заряда, которые ускорялись внутренними электрическими полями, существующими в пленке LT-GaAs. Спектры генерируемых ТГц-излучений одинаковы для обеих пленок, однако интенсивность спектра для пленки LT-GaAs (111)A в 3.6 раз больше. По сравнению с нелинейным кристаллом ZnTe пленки LT-GaAs (100) и LT-GaAs (111)A без приложения внешнего электрического поля генерируют на 1-2 порядка менее интенсивное ТГц-излучение. Наличие в спектре частоты порядка 0.1 ТГц связано с наличием шумового фона. Следует отметить, что наличие паров воды также снижает чувствительность установки в области линий поглощения. На частоте 1.67 ТГц виден небольшой провал в спектре, который соответствует интенсивному поглощению парами воды.

При подаче напряжения смещения 60В к контактам ФП антенны интенсивность генерации терагерцевого излучения по отношению к интенсивности без смещения сильно возросла: в 164 раза для ФП антенны на LT-GaAs $(100)$ и в 90 раз для ФП антенны на LT-GaAs (111)A. На рис. 4 показаны временны́е формы и частотные спектры ТГц-излучения от ФП антенн с приложенным напряжением смещения 60 В. Видно, что интенсивность излучения ФП антенны на LT-GaAs (111)A в 2 раза больше, чем интенсивность излучения ФП антенны на LT-GaAs (100). Спектры излучения ФП антенн похожи, их максимум лежит в области 1 ТГц, в то время как максимум спектра излучения кристалла $\mathrm{ZnTe}$ сдвинут в сторону бо́льших частот и находится в области 2 ТГц. Кроме того, ширина генерируемого спектра ТГц-частот в случае LT-GaAs оказывается выше для обоих типов образцов.

Зависимость интенсивности ТГц-излучения ФП антенны от напряжения смещения показана на рис. 5. Значительное повышение интенсивности наблюдается на фотопроводящей антенне LT-GaAs (111)A. Это повышение связано с бо́льшим фототоком, образующимся вследствие большей концентрации свободных носителей заряда в пленке LT-GaAs (111)A. Кроме того, зависимость интенсивности ТГц-излучения от напряжения смещения для антенны LT-GaAs (100) является сублинейной, тогда

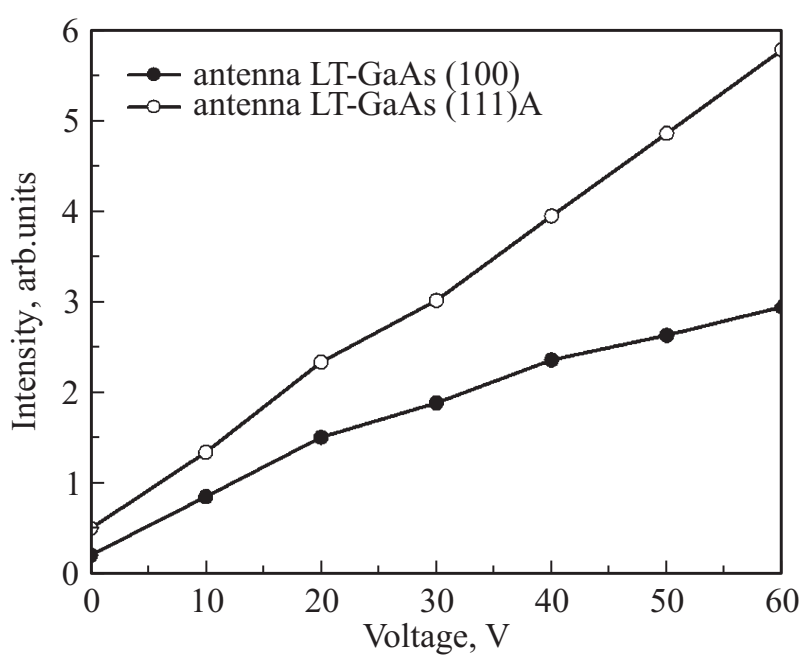

Рис. 5. Интенсивность излучения антенны в зависимости от напряжения смещения, нормированная на интенсивность излучения ZnTe. 

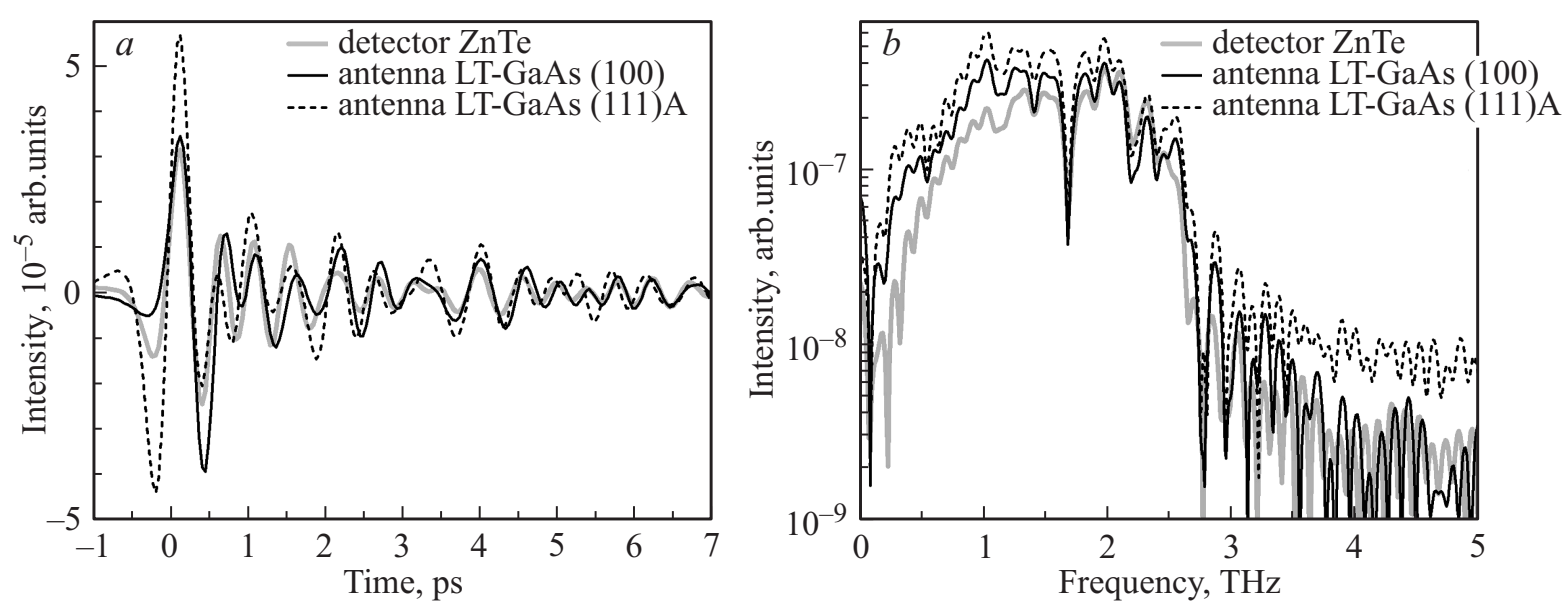

Рис. 6. Сравнение терагерцевых детекторов (генератор ТГц-излучения - кристалл ZnTe): $a$ - временна́я форма электрического импульса с трех типов детекторов; $b$ - частотный спектр электрического импульса с трех типов детекторов.

как для антенны LT-GaAs (111)A зависимость близка к линейной.

Также были исследованы детектирующие свойства ФП антенн на LT-GaAs (100) и LT-GaAs (111)A, ТГцизлучение при этом генерировалось нелинейным кристаллом ZnTe. На рис. 6 показаны временны́е формы и частотные спектры электрических ТГц-импульсов, измеренных ФП антеннами. Выявлено, что чувствительность ФП антенны на LT-GaAs $(111)$ A в 1.5 раза больше чувствительности ФП антенны на LT-GaAs (100), a также нелинейного кристалла ZnTe. Также видно, что общая ширина спектра электрического сигнала составляет 3 ТГц для всех детекторов. Однако в спектре сигнала, измеренного нелинейным кристаллом ZnTe, сравнительно более интенсивна область частот возле 2 ТГц, а в спектре сигналов, измеренных ФП антеннами, присутствует дополнительная интенсивная область вблизи 1 ТГц, благодаря которой спектр становится более однородным.

Низкочастотную область в спектрах излучения и чувствительности ФП антенн можно объяснить их топологией: антенна в виде двух параллельных полосковых контактов с расстоянием $d$ между ними является резонансной, ее резонансная частота определяется выражением

$$
d=\frac{\lambda}{2 \sqrt{\varepsilon_{\mathrm{eff}}}}=\frac{c}{2 f_{\mathrm{res}} \sqrt{\varepsilon_{\mathrm{eff}}}}, \quad \varepsilon_{\mathrm{eff}}=\frac{\varepsilon_{\mathrm{GaAs}}+1}{2}=7
$$

и равна 0.28 ТГц. Тем не менее, как показано в работе [14], в спектрах излучения полосковых ФП антенн не наблюдаются отчетливые пики, связанные с резонансными частотами. При изменении размеров ФП антенны спектр всего лишь несколько изменяет свою форму.

В результате более подробного анализа всех рассмотренных спектров (рис. $3, b, 4, b, 6, b$ ) получены численные характеристики спектров, которые приведены в таблице. Полоса излучения/чувствительности определялась как диапазон частот, в котором излучается/детектируется 50\% интегральной интенсивности, при этом интенсивность на граничных частотах $\left(f_{1 / 2}\right)_{\min }$ и $\left(f_{1 / 2}\right)_{\max }$ приблизительно одинакова.

\section{4. Заключение}

В данной работе показано, что пленки LT-GaAs на подложках GaAs (100) и (111)A генерируют ТГцизлучение в диапазоне до 3 ТГц при облучении их фемтосекундными импульсами лазера с длиной волны 800 нм. Сравнение пленок показывает, что интенсивность ТГц-излучения от пленки LT-GaAs на несингулярной подложке GaAs(111)A в 3.6 раза больше, чем от пленки LT-GaAs на сингулярной подложке GaAs (100). Интенсивность ТГц-излучения от ФП антенны в виде двух параллельных полосок Тi/Au шириной 100 мкм и с расстоянием между ними 200 мкм, изготовленных на поверхности этих пленок, при приложении напряжения 60 В к контактам антенны на 2 порядка превосходит интенсивность ТГц-излучения от соответствующих пленок без антенн. Сравнение ФП антенн показывает, что интенсивность ТГц-излучения от ФП антенны на LT-GaAs/GaAs (111)A в 2 раза больше, чем от такой же ФП антенны на LT-GaAs/GaAs (100), и в 4.5 раза превосходит интенсивность ТГц-излучения от нелинейного кристалла ZnTe.

Чувствительность ФП антенны на LT-GaAs/ GaAs (111)A, выступающей в роли детектора ТГц-излучения, в 1.4 раза превосходит чувствительность ФП антенны на LT-GaAs/GaAs (100) и в 1.8 раза превосходит чувствительность нелинейного кристалла ZnTe.

Как генератор ТГц-излучения, ФП антенна на LT-GaAs/GaAs (111)A значительно превосходит ФП антенну на LT-GaAs/GaAs $(100)$. В то же время, как детектор ТГц-излучения, ФП антенна на LT-GaAs/GaAs (111)A лишь ненамного лучше, чем ФП антенна на LT-GaAs/GaAs (100). 
Лучшие свойства ФП антенн на пленках LT-GaAs на подложках (111)A по сравнению с пленками LT-GaAs на подложках (100) следует приписать особенностям кристаллической структуры пленок LT-GaAs, образующимся при использовании несингулярной подложки $\mathrm{GaAs}(111) \mathrm{A}$ для эпитаксиального роста пленок.

Работа выполнена при финансовой поддержке Российского научного фонда (соглашение № 14-12-01080), Министерства образования и науки РФ (соглашение о предоставлении субсидии № 14.Z50.31.0034 и Государственное задание № 3.7331.2017/П220) и РФФИ (проект № 16-29-03294 офи_м).

\section{Список литературы}

[1] M. Venkatesh, K.S. Rao, T.S. Abhilash, S.P. Tewari, A.K. Chaudhary. Optical Mater., 36, 596 (2014).

[2] Г.Б. Галиев, Е.А. Климов, Д.В. Лаврухин, А.Э. Ячменев, Р.Р. Галиев, Д.С. Пономарев, Р.А. Хабибуллин, Ю.В. Федоров, А.С. Бугаев. Нано- и микросистемная техника, 6, 28 (2014).

[3] Z. Liliental-Weber, W. Swider, K.M. Yu, J. Kortright, F.W. Smith, A.R. Calawa. Appl. Phys. Lett., 58(19), 2153 (1991).

[4] Z.-Liliental-Weber, H.J. Cheng, S. Gupta, J. Whitaker, K. Nichols, F.W. Smith. J. Electron. Mater., 22 (12), 1465 (1993).

[5] M. Missous. Microelectronics J., 27, 393 (1996).

[6] B. Grandidier, Huajie Chen, R.M. Feenstra, D.T. McInturff, P.W. Juodawlkis, S.E. Ralph. Appl. Phys. Lett., 74, 1439 (1999).

[7] Patent US 8835853. Photoconductive element / Toshihiko Ouchi, Kousuke Kajiki; Canon Kabushiki Kaisha, Tokyo. Publication date 16.09.2014.

[8] J.-L. Coutaz, J.-F. Roux, A. Gaarder, S. Marcinkevicius, J. Jasinski, K. Korona, M. Kaminska, K. Bertulis, A. Krotkus. $X I$ Intern. Semiconducting and Insulating Material Conference (Canberra, Australia, July 3-7, 2000) p. 89.

[9] P. Specht, S. Jeong, H. Sohn, M. Luysberg, A. Prasad, J. Gebauer, R. Krause-Rehberg, E.R. Weber. Mater. Sci. Forum, 258-263, 251 (1997).

[10] Г.Б. Галиев, В.Г. Мокеров, В.В. Сарайкин, Ю.В. Слепнев, Г.И. Шагимуратов, Р.М. Имамов, Э.М. Пашаев. ЖТФ, 71 (4), 47 (2001).

[11] G. Galiev, V. Kaminskii, D. Milovzorov, L. Velihovskii, V. Mokerov. Semicond. Sci. Technol., 17 (2), 120 (2002).

[12] Г.Б. Галиев, Е.А. Климов, М.М. Грехов, С.С. Пушкарев, Д.В. Лаврухин, П.П. Мальцев. ФТП, 50 (2), 195 (2016).

[13] P. Uhd Jepsen, R.H. Jacobsen, S.R. Keiding. J. Opt. Soc. Am. B, 13 (11), 2424 (1996).

[14] Masahiko Tani, Shuji Matsuura, Kiyomi Sakai, Shin-ichi Nakashima. Appl. Optics, 36 (30), 7853 (1997).

[15] S.P. Kovalev, G.Kh. Kitaeva. JETP Lett., 94 (2), 95 (2011).

[16] C. Winnewisser, P. Uhd Jepsen, M. Schall, V. Schyja, H. Helm. Appl. Phys. Lett., 70, 3069 (1997).

\section{Generation and detection of terahertz radiation by low-temperature-grown epitaxial films GaAs on (100) and (111)A oriented GaAs substrates}

\author{
G.B. Galiev ${ }^{1}$, S.S. Pushkarev' ${ }^{1}$, A.M. Buriakov², \\ V.R. Bilyk ${ }^{2}$, E.D. Mishina ${ }^{2}$, E.A. Klimov' ${ }^{1}$, \\ I.S. Vasil'evskii ${ }^{3}$, P.P. Maltsev ${ }^{1}$ \\ ${ }^{1}$ Institute of Ultra High Frequency Semiconductor \\ Electronics, Russian Academy of Sciences, \\ 117105 Moscow, Russia \\ 2 Moscow Technological University „MIREA“, \\ 119454 Moscow, Russia \\ ${ }^{3}$ National Research Nuclear University „MEPhl“, \\ 115409 Moscow, Russia
}

Abstract The efficiency of generation and detection of terahertz radiation in the bandwidth up to $3 \mathrm{THz}$ by photoconductive stripline antennas on low-temperature-grown GaAs was investigated by means of time-domain terahertz spectroscopy. LT-GaAs films were grown by molecular beam epitaxy on substrates GaAs with orientation (100) and (111)A and contained equidistant Si $\delta$-layers. Generation and detection of Thz-radiation realized when LT-GaAs film or photoconductive antenna gap was illuminated by femtosecond $800 \mathrm{~nm}$ laser pulses. THz-radiation from LT-GaAs/ GaAs (111)A-based antenna was shown to be 2.0 more intensive than one from LT-GaAs/GaAs (100)-based antenna. The sensitivity of LT-GaAs/GaAs (111)A-based antenna was shown to be 1.4 times higher than one of LT-GaAs/GaAs (111)A-based antenna. 